\title{
Actinomycetes bioactivos de sedimento marino de la costa central del Perú
}

\author{
Bioactives Actinomycetes of marine sediment from the central coast of Peru
}

\author{
Jorge León', Libia Liza', Isela Soto', D’Lourdes Cuadra', Lilian Patiño²y Rito Zerpa²
}

\begin{abstract}
(1) Laboratorio de Microbiología Ambiental y Biotecnología, Facultad de Ciencias Biológicas, Universidad Nacional Mayor de San Marcos, Apartado 110058, Lima Perú.

E-mail Jorge León: jleonq@unmsm.edu.pe

(2) Laboratorio de Microbiología del Departamento de Patología, Instituto de Salud del Niño.
\end{abstract}

$\begin{array}{ll}\text { Presentado: } & 16 / 02 / 2007 \\ \text { Aceptado: } & 10 / 10 / 2007\end{array}$

\section{Resumen}

En el presente trabajo evaluamos la actividad antibacteriana y antifúngica de actinomycetes marinos sobre patógenos de origen clínico. Asimismo, fueron evaluadas la capacidad de producir enzimas extracelulares como carbohidrasas, lipasas y proteasas. Los Actinomycetes fueron aislados de sedimentos colectados entre setiembre a diciembre del 2005 de las Bahías de Ancón (Lima) e Independencia (Ica) de 34 y 100 m de profundidad. El aislamiento se realizó en Agar Caseína - Almidón (ACA) y Agar Marino (AM) con adición de Cicloheximide $(10 \mu \mathrm{g} / \mathrm{mL})$. Las evaluaciones antimicrobianas fueron realizadas frente a bacterias patógenas antibiótico-multirresistentes y hongos de origen clínico; en tanto, para evaluar su actividad multienzimática se utilizaron sustratos poliméricos diversos. Se aislaron un total de 62 actinomycetes, de los cuales 31 (50\%) mostraron actividad antibacteriana frente a Staphylococcus aureus, 36 (59\%) frente a Pseudomonas aeruginosa y $23(37 \%)$ a ambos patógenos. Las cepas de actinomycetes l-400A y M10-77 identificadas en cada caso como Streptomyces y Thermoactinomyces fueron las que exhibieron mayor actividad inhibitoria frente a $P$. aeruginosa y $S$. aureus respectivamente. Asimismo, 13 actinomycetes $(20,97 \%)$ mostraron actividad antifúngica frente a cultivos de Candida albicans cepa 1511 y 17 $(27,42 \%)$ frente a Candida albicans cepa $1511 \mathrm{MIC}$; sin embargo, ningún actinomycete presentó actividad inhibitoria frente a Aspergillus niger, Aspergillus fumigatus y Trichophyton mentagrophytes. La mayoría de los actinomycetes mostraron tener actividad multienzimática capaz de hidrolizar compuestos poliméricos como el tween-80 (96\%), la gelatina (95\%), almidón (93\%), lecitina (88\%) y la caseína (74\%). Extractos del compuesto activo obtenidos de la cepa M10-77 con etil acetato rindieron notable actividad inhibitoria contra $S$. aureus. Se concluye que el sedimento marino es fuente de Actinomycetes con gran capacidad de producir sustancias bioactivas de importancia médica-farmacológica e industrial.

Palabras clave: Sedimento marino, actinomycetes, patógenos multirresistentes, antibiosis.

\section{Abstract}

In the present research we evaluated the antibacterial and antifungical activity of marine actinomycetes over pathogen of clinical origin. Likewise, it was evaluated the capacity to produce extracellular enzymes like carbohidrases, lipases and proteases. The Actinomycetes were isolated from sediments collected between September to December 2005 of Ancón (Lima) and Independencia (Ica) Bays at depths of 34 and $100 \mathrm{~m}$. The isolation was performed in Casein - Starch Agar (CSA) and Marine Agar (AM) with addition of Cicloheximide $(10 \mu \mathrm{g} / \mathrm{mL})$. The antimicrobial evaluations were done comparing them with pathogenic antibiotic-multiresistant bacteria and fungi from clinical origin; in as much, to evaluate their multienzimatic activity several polimeric substrates were used. A total of 62 actinomycetes were isolated, 31 of there (50\%) showed antibacterial activity in opposite to Staphylococcus aureus, 36 (59\%) in opposite to Pseudomonas aeruginosa and $23(37 \%)$ to both pathogens. Strains of actinomycetes I-400A and M10-77 identified in each case like Streptomyces and Thermoactinomyces exhibited higher inhibitory activity against $S$. aureus and $P$. aeruginosa respectively. Also, 13 actinomycetes $(20,97 \%)$ showed to antifungical activity against cultures of Candida albicans strain 1511 and 17 (27,42\%) with Candida albicans strain 1511MIC; nevertheless, no actinomycete displayed inhibitory activity to the growth of Aspergillus niger, Aspergillus fumigatus and Trichophyton mentagrophytes. Most Actinomycetes showed to have multienzymic activity able to hydrolysis polymerics compounds like the tween-80 (96\%), gelatin (95\%), starch $(93 \%)$, lecitine $(88 \%)$ and casein $(74 \%)$. Extracts of the active compound obtained from the strain M10-77 with ethyl acetate produced a notable inhibitory activity against $S$. aureus. We conclude that the marine sediment is source of Actinomycetes with great capacity to produce bioactives substances of medical-pharmacological and industrial relevance.

Keywords: Marine sediment, actinomycetes, multiresistant pathogens, antibiosis.

\section{Introducción}

Las enfermedades infecciosas causadas por las bacterias y los hongos patógenos representan un desafío serio para la farmacología actual, pues así lo evidencian los millones de muertes prematuras que causan en el mundo (World Health Organization, 2002). Por otro lado, el rápido desarrollo de la resistencia antibiótica por muchos patógeno, y la toxicidad de algunos de los antibióticos actualmente usados propicia la búsqueda y el desarrollo constante de nuevos agentes antimicrobianos (Leiva et al., 2004). Los microorganismos, especialmente bacterias que pertenecen al orden Actinomycetal, son los productores más comunes de agentes antimicrobianos. Tradicionalmente, estos organismos fueron aislados de fuentes terrestres, y solo en las dos últimas décadas llegó a ser evidente el potencial de microorganismos marinos como productores de antibióticos, aislándose a muchas bacterias productoras de nuevos antibióticos 
con estructuras únicas y características muy propias del ambiente marino (Maldonado et al., 2005). El orden Actinomycetal está compuesto por aproximadamente 80 géneros, en su mayoría aislados de fuentes terrestres donde cumplen un rol muy importante como organismos saprofíticos (Williams et al., 1984). Los actinomycetes está formado por grupos de microorganismos filamentosos Gram positivos, con alto contenido de $\mathrm{G}+\mathrm{C}$ en su DNA, de amplia distribución en la naturaleza y muy conocidos por producir antibióticos naturales y otros importantes compuestos bioactivos de interés comercial e industrial (Magarvey et al., 2004). En la actualidad, los actinomycetes se procuran de aislar a partir de nuevas fuentes y continúan siendo objeto de estudio en la búsqueda de nuevas substancias con diversas propiedades biológicas tales como metabolitos antimicrobianos, antivirales, anticancerígenos, anticoagulantes, inmunomoduladores entre otros (Bull et al., 2000; Mincer et al., 2002; Kokare et al., 2004). En las últimas décadas, la búsqueda de actinomycetes se ha reorientado hacia otros ambientes como: sedimentos de ríos, lagos y océanos que ofrecen la posibilidad de encontrar cepas silvestres no descritas que produzcan nuevos metabolitos secundarios farmacológicamente activos (Jian y Xu, 1996; Bull et al., 2005; Ward y Bora, 2006)). Asimismo, en los últimos años, el número de nuevos compuestos de interés médico-farmacológico obtenidos de géneros de actinomycetes de origen terrestre ya conocidos ha decrecido; en cambio a partir de actinomycetes marinos principalmente de las familias Streptomycetaceae y Micromonosporaceae han ido en aumento en cantidades cada vez mayores, considerándose por ello como virtuales productores prolíficos de importantes metabolitos secundarios (Kelecom, 2002; Jensen et al., 2005; Fiedler et al., 2005). Por otro lado, el incremento vertiginoso de patógenos drogo-resistentes que pone en riesgo el futuro de las terapias antimicrobianas, ha motivado la búsqueda de nuevas cepas a partir de nuevas fuentes y el desarrollo de nuevas estrategias combinatorias en la síntesis química y su aplicación antimicrobiana (Saadoun et al., 1999; Projan y Youngman, 2002; Sujatha et al., 2005). A la fecha, numerosos estudios sobre actinomycetes marinos resaltan la importancia de estos microorganismos en la obtención de nuevos productos naturales, muchos de los cuales tienen potencial aplicación biomédica en la terapia antimicrobiana (Magarvey et al., 2004; Augustine et al., 2005). Debido a que los ecosistemas marinos difieren notablemente de los terrestres, las capacidades metabólicas y fisiológicas de los actinomycetes marinos son también diferentes, lo que ofrece un enorme potencial de descubrimiento de nuevas drogas, las cuales se espera que actúen contra diversas bacterias, hongos y levaduras. Si bien la síntesis química de drogas es una opción válida, la búsqueda de compuestos a partir de microorganismos continúa siendo la principal fuente de nuevos antimicrobianos. Algunos estudios reportan que las cepas de actinomycetes pueden exhibir un amplio espectro de inhibición tanto sobre bacterias Gram negativas, Gram positivas y hongos; esto puede significar que el agente activo no es muy específico en cuanto a su diana ya que actúa igualmente sobre procariotas y eucariotas, o bien el actinomycete pueda elaborar más de un metabolito y que cada uno de ellos tenga un sitio blanco específico distinto (Leiva et al., 2004). El objetivo del presente trabajo fue evaluar las características culturales de actinomycetes aislados de sedimento marino de la costa central del Perú y determinar su actividad antibacteriana y antifúngica frente a patógenos de origen clínico. Complementariamente, se evalúa la capacidad de producir diversas enzimas extracelulares de interés biotecnológico.

\section{Material y Métodos Muestreo}

Mediante campañas mensuales se tomaron un total de 24 muestras de sedimento marino de 34 y $100 \mathrm{~m}$ de profundidad, las que fueron recolectadas mediante el método del dragado en la Bahía de Ancón (Lima) y Bahía de Independencia (Paracas -Ica) (Tabla 1). Las muestras fueron colocadas en tubos estériles y transportadas en cajas térmicas en refrigeración $\left(4^{\circ} \mathrm{C}\right)$, las que fueron procesadas posteriormente para el análisis microbiológico en el Laboratorio de Microbiología Ambiental y Biotecnología del Instituto de Ciencias Biológicas Antonio Raimondi de la Universidad Nacional Mayor de San Marcos.

\section{Procesamiento de muestras y aislamiento de acti- nomycetes marinos}

Previo al aislamiento de los actinomycetes y con la finalidad de eliminar la microbiota vegetativa que acompańa la muestra, éstas fueron procesadas por dos métodos: el método I (húmedo), que consiste en pesar $20 \mathrm{~g}$ de muestra y colocar en placas estériles para someter a un tratamiento térmico en baño maría; el método II (seco), un procedimiento similar al anterior pero colocando las muestras en una estufa en calor seco. En ambos casos la temperatura de tratamiento fue de $50^{\circ} \mathrm{C}$ por 60 minutos (Pisano et al., 1986; Takizawa et al., 1993). Después de estos tratamientos se hicieron diluciones consecutivas al décimo en agua de mar estéril hasta $10^{-5}$. De cada muestra diluida se sembró $0,1 \mathrm{~mL}$ en placas de Agar Marino (AM) y Agar Caseína-Almidón (ACA) preparados con agua de mar natural y con adición de Cycloheximide $(10 \mu \mathrm{g} / \mathrm{mL})$ como agente antifúngico. Los cultivos fueron incubados a $28{ }^{\circ} \mathrm{C}$ durante 15 a 20 días (Kokare et al., 2004). Se aislaron las colonias características de actinomycetes y se mantuvieron en ceparios de Agar Marino más glicerina (20\% v/v) para estudios posteriores.

\section{Caracterización de cultivos de actinomycetes}

Las características morfológicas, fisiológicas, bioquímicas y de cultivo de actinomycetes aislados se realizaron siguiendo la metodología y la guía práctica para identificación de Actinomycetes según esquemas de Holt et al. (1994). Las características culturales de colonias de actinomycetes marinos en medio líquido

Tabla 1. Lugares de colecta de muestras de sedimento para el aislamiento de Actinomycetes marinos (setiembre - diciembre de 2005).

\begin{tabular}{|c|c|c|}
\hline \multirow[b]{2}{*}{ Lugares de colecta } & \multicolumn{2}{|c|}{ Profundidad de colecta (m) } \\
\hline & 34 & 100 \\
\hline \multicolumn{3}{|l|}{ Bahía de Ancón: } \\
\hline Ubicación geográfica & $\left(11^{\circ} 76 \mathrm{~S} ; 77^{\circ} 20 \mathrm{~W}\right)$ & $\left(11^{\circ} 81 \mathrm{~S} ; 77^{\circ} 39 \mathrm{~W}\right)$ \\
\hline $\begin{array}{l}\text { Fecha de colecta } \\
\text { ( } \mathrm{N}^{\mathrm{o}} \text { de muestras) }\end{array}$ & 30 set. 2005 (6) & 30 set. 2005 (6) \\
\hline \multicolumn{3}{|l|}{ Bahía Independencia: } \\
\hline \multirow[t]{2}{*}{ Ubicación geográfica } & $\left(14^{\circ} 26 \mathrm{~S} ; 76^{\circ} 17 \mathrm{~W}\right)$ & $\left(14^{\circ} 34 \mathrm{LS} ; 76^{\circ} 18 \mathrm{~W}\right)$ \\
\hline & 25 oct. 2005 (2) & 25 oct. 2005 (2) \\
\hline \multirow[t]{2}{*}{$\begin{array}{l}\text { Fecha de colecta } \\
\text { ( } \mathrm{N}^{\circ} \text { de muestras) }\end{array}$} & 05 nov. 2005 (2) & 05 nov. 2005 (2) \\
\hline & 22 dic. 2005 (2) & 22 dic. 2005 (2) \\
\hline $\mathrm{N}^{o}$ total de muestras & (12) & (12) \\
\hline
\end{tabular}


y sólido fueron descritas según su crecimiento en el Caldo Marino y Agar Marino respectivamente. Las observaciones microscópicas se realizaron a partir de microcultivos luego de su crecimiento por el método de "bloques de agar" y/o "laminilla en plano inclinado" e incubados en cámara húmeda a $28^{\circ} \mathrm{C}$ por $5-7$ días.

\section{Actividad enzimática de los actinomycetes marinos}

La producción de enzimas extracelulares (proteasas y carbohidrasas) de los actinomycetes se determinó por pruebas convencionales seguidos por León et al. (2000) según el método de difusión radial en placas con Agar Marino más el sustrato específico consistente de caseína (1\%), gelatina (5\%) y almidón $(2 \%)$. Asimismo, la producción de lipasas como esterasas y lecitinasas se determinaron utilizando Tween 80 y yema de huevo estéril como sustratos respectivos. En todos los casos se incubaron a $20^{\circ} \mathrm{C}$ hasta por 21 días. La determinación cualitativa positiva se determinó midiendo los halos de actividad en la zona de crecimiento de los actinomycetes.

\section{Determinación de la actividad antibiótica \\ Cepas indicadoras}

Las cepas patógenas multi-drogo-resistentes de Pseudomonas aeruginosa y Staphylococcus aureus, así como de Candida albicans fueron otorgadas por los laboratorios respectivos de Microbiología y Micología del Instituto Especializado de Salud del Niño. Los hongos miceliales fueron proporcionados por el Laboratorio de Micología del Instituto de Medicina Tropical Daniel Alcides Carrión, Universidad Nacional Mayor de San Marcos.

\section{Actividad antibacteriana}

Se realizó mediante el método de "doble capa" de Westerdahl et al., (1991) modificado por León y García-Tello (1998). Los actinomycetes fueron sembrados como macrocolonias en Agar Marino $\mathrm{pH} 7,6$ e incubadas a $28{ }^{\circ} \mathrm{C}$ por $5-7$ días. Para las pruebas de antagonismo las cepas testigo de $P$. aeruginosa y $S$. aureus fueron previamente reactivadas en Caldo Tripticasa Soya y luego ajustadas a $10^{6} \mathrm{UFC} / \mathrm{mL}$. Las pruebas de antagonismo se realizaron mediante la inoculación de cepas testigo en medio semisólido a modo de "segunda capa" sobre los cultivos de los actinomycetes marinos. Las placas en prueba fueron incubadas a 37 'C por 24 a 48 h, realizándose luego las lecturas correspondientes mediante la medida del radio de los halos de inhibición.

\section{Actividad antifúngica}

La determinación de la actividad de los actinomycetes marinos frente a hongos levaduriformes se realizó de modo similar que para las bacterias. Las cepas de Candida albicans se agregaron sobre los actinomycetes a modo de segunda capa previamente preparados en el medio semisólido Extracto de Levadura-Peptona-Glucosado (YPG), las que fueron incubadas a $35-37{ }^{\circ} \mathrm{C}$ por $24-48 \mathrm{~h}$. La actividad antifúngica se determinó midiendo el radio de los halos de inhibición. La actividad antifúngica de actinomycetes frente a hongos filamentosos patógenos, se determinó según procedimientos seguidos por Zaror y EspinelIngroff (1989). Las cepas en prueba incluyeron a Aspergillus niger, Aspergillus fumigatus y Trichophyton mentagrophytes.

\section{Extracción del compuesto activo y prueba de su actividad inhibitoria}

Los compuestos antibacterianos de una cepa seleccionada de actinomycete marino (cepa M10-77) fueron recobrados medi- ante extracción con Etil Acetato según procedimientos descritos por Zheng et al. (2004). El cultivo del actinomycete se realizó en el Caldo Marino y mantenido en constante agitación a 150 rpm a $20^{\circ} \mathrm{C}$ durante 15 días. El caldo se filtró y se trató con Etil Acetato (v/v) y agitado vigorosamente por una hora. La fase orgánica conteniendo el compuesto activo fue separada de la fase acuosa y luego evaporada hasta sequedad. El residuo obtenido fue usado para determinar la actividad antibacteriana frente a $S$. aureus cepa 457.

\section{Resultados y discusión \\ Enriquecimiento y aislamiento de actinomycetes marinos}

De las muestras de sedimento procesadas por el método I (calor húmedo) y sembradas en Agar Caseína-Almidón, se llegaron a recuperar colonias de actinomycetes en el 50\% del total de placas sembradas; en tanto, las que fueron sembradas en Agar Marino tuvieron mejor rendimiento llegando a alcanzar el 75\% de placas con crecimiento característico de actinomycetales. Por otro lado, a partir de las muestras tratadas por el método II (calor seco) y sembradas en Agar Caseína-Almidón solo en el 12\% de ellas hubo crecimiento favorable a actinomycetes, mientras que en el Agar Marino alcanzaron hasta el 25\% de crecimiento. Sin duda, el pretratamiento de la muestra en calor fue eficaz para restringir el crecimiento de la flora acompañante, ya que en la mayoría de los cultivos se obtuvo colonias puras de actinomycetes. Estos resultados fueron similares a los obtenidos por Pisano et al. (1986), quienes además del calor aplicaron tratamientos con fenol y posterior cultivo en agar quitina. En nuestro estudio, como resultado de ambos métodos se llegaron a aislar un total de 62 cepas de actinomycetes marinos cuyas características culturales se indican en la Tabla 2. El protocolo de aislamiento que resultó más factible para obtener mayor número de cepas de actinomycetes marinos fue aquel en el que se realizó el tratamiento térmico húmedo y el cultivo en Agar Marino (75\% de rendimiento). Este resultado difiere de otros trabajos, puesto que el Agar Marino muy útil generalmente en el aislamiento de heterótrofos marinos no es utilizado necesariamente para el aislamiento de actinomycetes, pero sí el Agar Caseína-Almidón, Agar Czapeck y otros medios enriquecidos, los cuales según otros autores (Pisano et al., 1986; Takizawa et al., 1993) tuvieron un óptimo rendimiento para la recuperación de actinomycetes marinos. En nuestro caso, el Agar Caseína-Almidón y el Agar Czapeck fueron ocasionalmente utilizados y tuvieron un rendimiento discreto.

\section{Características culturales de los actinomycetes}

Las características de cultivo tanto en medio sólido como líquido de los 62 aislados de actinomycetes se muestran en la Tabla 2. En Agar Marino los actinomycetes iniciaron su crecimiento generalmente a partir de 5-7 días de incubación hasta los 21 días. Formaron colonias de tamaño variable (desde pequeñas menores a $1 \mathrm{~mm}$ hasta colonias de $12 \mathrm{~mm}$ de diámetro). La mayoría (65\%) formaron inicialmente colonias ligeramente húmedas y algo brillosas, pero con el transcurrir del tiempo se volvieron opacas y secas adquiriendo una apariencia yesosa y pulverulenta. Todo esto hacía referencia a los estados de conversión por los que pasan las hifas aéreas hasta llegar a la formación de esporas (conidias).

Se pudo observar que existe una variedad de formas de colonia de actinomycetes marinos, siendo las más frecuentes las 
Tabla 2. Características culturales de actinomycetes aislados de sedimentos marinos.

\begin{tabular}{|c|c|c|}
\hline \multirow[b]{2}{*}{ Cepas } & \multicolumn{2}{|c|}{ Características de colonia } \\
\hline & Medio líquido (Caldo Marino) & Medio sólido (Agar Merino) \\
\hline M11-105 & Blancas, crecen a lo largo del tubo y en superficie. & $\begin{array}{l}\text { anca, circular, } 10 \mathrm{~mm} \text { de diámetro, bordes irregulares, y } \\
\text { n pigmento. }\end{array}$ \\
\hline M11-106 & $\begin{array}{l}\text { Blanca-yesosa en superficie y fondo del tubo con pequeños } \\
\text { conglomerados miceliales en el caldo. }\end{array}$ & $\begin{array}{l}\text { Circular, } 20 \mathrm{~mm} \text { de diámetro, de bordes regulares, sin pre- } \\
\text { sencia de pigmento. }\end{array}$ \\
\hline M11-110 & $\begin{array}{l}\text { Blancas, circulares, crecen en super } \\
\text { color rojizo en la base de la colonia. }\end{array}$ & $\begin{array}{l}\text { Blanco-rojiza, yesosa, } 8 \mathrm{~mm} \text { de diámetro, bor } \\
\text { pulverulenta, pigmento rojizo bajo la colonia. }\end{array}$ \\
\hline M11-115 & $\begin{array}{l}\text { Blanca-yesosa en toda la superficie del medio de cultivo, } \\
\text { sedimento blanquecino. }\end{array}$ & $\begin{array}{l}\text { Blanco-yesosa, } 20 \mathrm{~mm} \text { de diámetro, borde irregular, expansiva, } \\
\text { centro pulverulenta. }\end{array}$ \\
\hline M11-118 & $\begin{array}{l}\text { Blancas, pulverulentas en toda la superficie del cultivo, color- } \\
\text { ación rojo-marrón en el fondo. }\end{array}$ & $\begin{array}{l}\text { Blanca, circular, } 8 \mathrm{~mm} \text { de diámetro, borde irregu } \\
\text { claro, convexa, costrosa, centro pulverulenta. }\end{array}$ \\
\hline M11-120 & $\begin{array}{l}\text { Blanca-yesosas, micelio aéreo p } \\
\text { al tubo, sedimento escaso. }\end{array}$ & Blanca, circular, borde irregular lobulado, centro crema. \\
\hline M11-12 & $\begin{array}{l}\text { Ausencia de colonias en superficie pero abundantes en el } \\
\text { fondo. Colonias blanquecinas. }\end{array}$ & ostrosa, con perímetro membranoso marrón claro. \\
\hline M11-123 & $\begin{array}{l}\text { Abundantes colonias pequeñas en superficie, sedimento mic- } \\
\text { elial de color blanquecino. }\end{array}$ & $\begin{array}{l}\text { Blanca-grisácea, yesosa, circular, } 5 \mathrm{~mm} \text { de diámetro, poco } \\
\text { elevada, borde entero amarillento, aspecto membranoso. }\end{array}$ \\
\hline M11-125 & superficie, micelio corto sedimentado & $\begin{array}{l}\text { uperficie algodonosa, } 10 \mathrm{~mm} \text { de diámetro, ligeran } \\
\text { ada, borde regular, pigmento anaranjado bajo la c }\end{array}$ \\
\hline M11-131 & , escaso micelio sedimen- & $\begin{array}{l}\text { ircular, } 5 \mathrm{~mm} \text { de di } \\
\text { orrugada, ligerament }\end{array}$ \\
\hline M11-133 & $\begin{array}{l}\text { Blanca en toda la superficie, ausencia micelial en el caldo, } \\
\text { presencia de micelio sedimentado. }\end{array}$ & $\begin{array}{l}\text { Colonias irregulares, superficie pulverulenta, aplanadas, hifas } \\
\text { aéreas de color beige, pigmento rojo bajo la colonia. }\end{array}$ \\
\hline EM-2005 & undante en sedimentado. & borde irregula \\
\hline M10-85 & & $\begin{array}{l}\text { orde } \\
\text { tho. }\end{array}$ \\
\hline M12-141 & $\begin{array}{l}\text { Blanquecina con exudado en toda la superficie, pulverulenta, } \\
\text { abundante micelio profundo. }\end{array}$ & lanca-yesosa, $8 \mathrm{~mm}$ de diámetro, borde \\
\hline M10-77 & $\begin{array}{l}\text { lomiza y algo h } \\
\text { lento y cultivo t }\end{array}$ & $\begin{array}{l}\text { omizas, circ } \\
\text { gmento mar }\end{array}$ \\
\hline AC16 & $\begin{array}{l}\text { perficie, sedimento amarillento y medio de } \\
\text { e. }\end{array}$ & lente rojiza, plana, sin pigment \\
\hline I-34A & Blanca con exudado en superficie, micelio sedimentado. & $\begin{array}{l}\text { lanca-yesosa, circ } \\
\text { entrica, corrugad }\end{array}$ \\
\hline I-34B & omiza en su & lomiza circular $9 \mathrm{~mm}$ de diámetro \\
\hline I-234 & uperficie, micelio profundo & lom \\
\hline I-334A & & Colonia circular, $5 \mathrm{~mm}$ de diámetro. \\
\hline I-334B & $\begin{array}{l}\text { Grande, blanco-rojizo-yesoso, presencia de micelio sedimen- } \\
\text { tado y medio de cultivo transparente. }\end{array}$ & aciones aactilliorm \\
\hline $\mathrm{I}-434 \mathrm{~A}$ & Plomiza con puntos blancos & omiza. $13 \mathrm{~ms}$ r s \\
\hline I-434B & omiza-yesosa aloo & $\begin{array}{l}\text { Plomiza, circular, } 15 \mathrm{mr} \\
\text { lenta, borde blanco, lig }\end{array}$ \\
\hline I-534 & 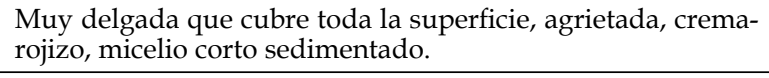 & $\begin{array}{l}\text { Blanca-yesosa, circular, } 10 \mathrm{~m} \\
\text { lenta, pigmento marrón baj }\end{array}$ \\
\hline I-100A & Delgada, blanca-yesosa, agriet & Iomiza onaca $15 \mathrm{~m}$ \\
\hline I-100B & anca-plomiza en superficie, abund & $\begin{array}{l}\text { Plomiza, } 6 \mathrm{~mm} \text { de diámetro, borde irregular, superficie pul- } \\
\text { verulenta, concéntrica, pigmento naranja bajo la colonia. }\end{array}$ \\
\hline $\mathrm{I}-300 \mathrm{~A}$ & Plomiza, grande, seca, con puntos blar & $\begin{array}{l}\text { Plomiza, } 8 \mathrm{~mm} \text { de diámetro, poco elevada, pulverulenta, } \\
\text { pigmento anaranjado bajo la colonia. }\end{array}$ \\
\hline I-300B & $\begin{array}{l}\text { Ploma, seca, con algunas zonas blancas, micelio profundo, } \\
\text { escaso micelio sedimentado. }\end{array}$ & $\begin{array}{l}\text { Plomiza claro, borde } \\
\text { micelio aéreo, sin pig }\end{array}$ \\
\hline I-300C & $\begin{array}{l}\text { Color plomo, ciertas zonas húmedas y puntos blanquecinos, } \\
\text { micelio profundo y sedimentado. }\end{array}$ & $\begin{array}{l}\text { Plomiza, } 8 \mathrm{~mm} \text { de diámetro, circular, borde irregular, pulveru- } \\
\text { lenta, puntos blancos en los bordes. }\end{array}$ \\
\hline $0 \mathrm{~A}$ & $\begin{array}{l}\text { Plomiza, seca, puntos blancos en superficie, conglomerado } \\
\text { de hifas en el cultivo. }\end{array}$ & $\begin{array}{l}\text { Plomiza, circular, } 1 \mathrm{~mm} \text { de diámetro, seca, borde entero de } \\
\text { color blanco, sin pigmento. }\end{array}$ \\
\hline $\mathrm{I}-400 \mathrm{~B}$ & $\begin{array}{l}\text { Plomiza, puntos blancos en superficie y a los bordes del tubo, } \\
\text { conglomerado de micelios en sedimento. }\end{array}$ & $\begin{array}{l}\text { Plomiza opaca, 1,5 mm de diámetro, borde irregular b } \\
\text { yesoso, sin pigmento bajo la colonia. }\end{array}$ \\
\hline
\end{tabular}


Tabla 2. Continuación.

\begin{tabular}{|c|c|c|}
\hline $\mathrm{I}-400 \mathrm{C}$ & $\begin{array}{l}\text { Pequeñas, blancas, planas, con bordes lisos, poco micelio } \\
\text { profundo pero abundante en sedimento. }\end{array}$ & $\begin{array}{l}\text { Plomiza, } 4 \mathrm{~mm} \text { de diámetro, borde poco irregular, puntos } \\
\text { blancos sobre la colonia, sin pigmento bajo la colonia. }\end{array}$ \\
\hline II-334A & $\begin{array}{l}\text { Grande, plomiza, con puntos blancos, pequeñas hifas en cul- } \\
\text { tivo, micelio profundo pero escaso en el sedimento }\end{array}$ & $\begin{array}{l}\text { Plomiza, circular, } 13 \mathrm{~mm} \text { de diámetro, corrugada, se observa } \\
\text { un borde adicional muy delgado de color blanco. }\end{array}$ \\
\hline II-334B & $\begin{array}{l}\text { Grande, plomiza, opaca, pulverulenta, con puntos blancos, } \\
\text { micelio profundo y poco en el sedimento. }\end{array}$ & $\begin{array}{l}\text { Plomiza oscura, circular, } 8 \mathrm{~mm} \text { de diámetro, borde regular, y } \\
\text { borde adicional de color blanco. }\end{array}$ \\
\hline II-334C & Grisácea, pulverulenta en superficie y puntos blancos. & $\begin{array}{l}\text { Plomiza, } 10 \mathrm{~mm} \text { de diámetro, pulverulenta, corrugada, puntos } \\
\text { blancos y bordes blanco, ligeramente elevada. }\end{array}$ \\
\hline II-534 & $\begin{array}{l}\text { Blanco-amarillento-yesosa, escaso micelio profundo y algunos } \\
\text { conglomerados en el cultivo y sedimento. }\end{array}$ & $\begin{array}{l}\text { Blanca-yesosa, circular, } 2 \mathrm{~mm} \text { de diámetro, elevada, pigmento } \\
\text { guinda bajo la colonia. }\end{array}$ \\
\hline II-300A & $\begin{array}{l}\text { Blanca-yesosa, llana, pocos conglomerados de micelio en el } \\
\text { cultivo, presencia de micelio sedimentado. }\end{array}$ & Plomiza, circular, 5 mm de diámetro, concéntrico. \\
\hline II-300B & $\begin{array}{l}\text { Crema-yesosa, agrietada, poco micelio profundo, y algunos } \\
\text { conglomerados en el cultivo y sedimento. }\end{array}$ & $\begin{array}{l}\text { Crema-yesosa, circular, } 5 \mathrm{~mm} \text { de diâmetro, borde irregular } \\
\text { con proyecciones concéntricas. }\end{array}$ \\
\hline II-400A & $\begin{array}{l}\text { Blanca-yesosa, poco micelio profundo, pequeños conglomera- } \\
\text { dos en el cultivo y abundante en sedimentos. }\end{array}$ & $\begin{array}{l}\text { Blanca-yesosa, circular, } 7 \mathrm{~mm} \text { de diâmetro, bordes dactili- } \\
\text { formes. }\end{array}$ \\
\hline II-400B & $\begin{array}{l}\text { Blanca-yesosa, poco abrupta, micelio profundo corto, con- } \\
\text { glomerado de micelios sedimentados. }\end{array}$ & $\begin{array}{l}\text { Blanco claro, yesosa, } 6 \mathrm{~mm} \text { de diâmetro, pigmento crema bajo } \\
\text { la colonia, bordes irregulares, llana. }\end{array}$ \\
\hline III-234A & $\begin{array}{l}\text { Crema-marrón, yesosa, micelio profundo uniforme, sin con- } \\
\text { glomerados y abundante micelio sedimentado. }\end{array}$ & $\begin{array}{l}\text { Beige, yesosa, } 7 \mathrm{~mm} \text { de diámetro, pulverulenta, ligeramente } \\
\text { elevada, borde irregular, pigmento rojizo bajo la colônia. }\end{array}$ \\
\hline III-234B & $\begin{array}{l}\text { Única en superficie, poco abrupta, blanco-yesosa, poco micelio } \\
\text { profundo y sedimentado. }\end{array}$ & $\begin{array}{l}\text { Blanca-yesosa, circular, } 5 \mathrm{~mm} \text { de diámetro, borde irregular, } \\
\text { elevada, pigmento marrón claro bajo la colonia. }\end{array}$ \\
\hline III-234C & $\begin{array}{l}\text { Blanca, yesosa, abrupta, pigmento marrón en la base, micelio } \\
\text { profundo, conglomerado en sedimento. }\end{array}$ & $\begin{array}{l}\text { Blanca-yesosa, circular, } 3 \mathrm{~mm} \text { de diâmetro, borde poço irregu- } \\
\text { lar, elevada, pigmento marrón verde bajo la colônia. }\end{array}$ \\
\hline III-234D & $\begin{array}{l}\text { Abrupta, blanco-café, micelio profundo uniforme, poco micelio } \\
\text { libre y conglomerados en sedimento. }\end{array}$ & $\begin{array}{l}\text { Blanca-yesosa, } 7 \mathrm{~mm} \text { de diámetro, corrugada, ligeramente } \\
\text { elevada, pigmento amarillento. }\end{array}$ \\
\hline III-234E & $\begin{array}{l}\text { Blanco-marrón, yesosa, abrupta, agrietada, larga prolongación } \\
\text { micelial en la base, micelio sedimentado. }\end{array}$ & $\begin{array}{l}\text { Beige-yesosa, bordes irregulares, ligeramente elevada, presen- } \\
\text { cia de pigmento de color rojo. }\end{array}$ \\
\hline III-434A & $\begin{array}{l}\text { Blanca, yesosa, poco abrupta, sin micelio profundo, pero con- } \\
\text { glomerados en el cultivo, micelio sedimentado. }\end{array}$ & $\begin{array}{l}\text { Blanca-yesosa, borde irregular, pulverulenta, poço elevada, } \\
\text { presencia de pigmento color marrón. }\end{array}$ \\
\hline III-434B & $\begin{array}{l}\text { Blanca, seca, delgada, plana, micelio profundo, conglomerados } \\
\text { en el cultivo y en el sedimento. }\end{array}$ & $\begin{array}{l}\text { Plomiza, circular, } 1 \mathrm{~mm} \text { de diámetro, aspecto pulverulento, } \\
\text { de borde regular, sin presencia de pigmento. }\end{array}$ \\
\hline III-434C & $\begin{array}{l}\text { Blanca, yesosa, sin micelio profundo, escasos conglomerados } \\
\text { y micelio sedimentado }\end{array}$ & $\begin{array}{l}\text { Colonia circular de } 1 \mathrm{~mm} \text { de diâmetro, de borde regular, de } \\
\text { color plomo oscuro, concéntrica y elevada em el centro. }\end{array}$ \\
\hline III-434D & $\begin{array}{l}\text { Blanca, yesosa, agrietada, abrupta, escaso micelio profundo, } \\
\text { algunos conglomerados y sedimento marrón. }\end{array}$ & $\begin{array}{l}\text { Circular, } 4 \mathrm{~mm} \text { de diámetro, borde irregular con prolonga- } \\
\text { ciones dactiliformes. }\end{array}$ \\
\hline III-434E & $\begin{array}{l}\text { Blanca, yesosa, poco abrupta, sin micelio profundo pero con } \\
\text { micelio sedimentado de color verde claro. }\end{array}$ & $\begin{array}{l}\text { Crema-opaca, borde irregular, pulverulenta, poco elevada, } \\
\text { pigmento marrón bajo la colonia. }\end{array}$ \\
\hline III-434F & $\begin{array}{l}\text { Blanca, yesosa, poco abrupta, agrietada, poco micelio pro- } \\
\text { fundo, micelio sedimentado. }\end{array}$ & $\begin{array}{l}\text { Blanca-yesosa, irregular, pulverulenta, crateriforme, bordes } \\
\text { dactiliformes, pigmento marrón bajo la colonia. }\end{array}$ \\
\hline III-200A & $\begin{array}{l}\text { Blanca, yesosa, pigmentación verdosa en la parte inferior de } \\
\text { la colonia, micelio sedimentado. }\end{array}$ & $\begin{array}{l}\text { Blanca-yesosa, } 10 \mathrm{~mm} \text { de diámetro, borde irregular, pulveru- } \\
\text { lenta, pigmento marrón bajo la colonia. }\end{array}$ \\
\hline III-200B & $\begin{array}{l}\text { Blanca, yesosa, agrietada, micelio profundo corto, micelios } \\
\text { conglomerados y sedimentados. }\end{array}$ & $\begin{array}{l}\text { Blanca-yesosa, } 12 \mathrm{~mm} \text { de diámetro, pulverulenta, bordes } \\
\text { dactiliformes, pigmento marrón bajo la colonia. }\end{array}$ \\
\hline III-200C & $\begin{array}{l}\text { Blanca, yesosa, poco abrupta, agrietada, poco micelio pro- } \\
\text { fundo, micelio sedimentado marrón verdoso oscuro. }\end{array}$ & $\begin{array}{l}\text { Blanca-yesosa, circular, } 11 \mathrm{~mm} \text { de diámetro, elevad, puntos } \\
\text { blanquecinos en todo el borde de la colonia. }\end{array}$ \\
\hline III-200D & $\begin{array}{l}\text { Blanca, yesosa, agrietada, micelio profundo, micelio sedimen- } \\
\text { tado de color marrón verdoso claro. }\end{array}$ & $\begin{array}{l}\text { Crema-yesosa, } 1 \mathrm{~mm} \text { de diámetro, bordes irregulares, con } \\
\text { prolongaciones dactiliformes. }\end{array}$ \\
\hline III-200EB & $\begin{array}{l}\text { Blanca, yesosa poco abrupta, no se observa micelio profundo, } \\
\text { cultivo cristalino y micelio sedimentado }\end{array}$ & Colonias pequeñas, blanca-rosáceas borde entero. \\
\hline III-200F & $\begin{array}{l}\text { Crema, yesosa, corto micelio profundo, medio de cultivo } \\
\text { cristalino, presencia de micelio sedimentado. }\end{array}$ & $\begin{array}{l}\text { Blanca-yesosa, circular, } 4 \mathrm{~mm} \text { de diâmetro, borde regular, } \\
\text { poço elevada. }\end{array}$ \\
\hline III-200G & $\begin{array}{l}\text { Blanca, yesosa, sin micelio profundo, pigmento marrón debajo } \\
\text { de la colonia, micelio sedimentado. }\end{array}$ & $\begin{array}{l}\text { Blanco-crema, yesosa, borde irregular con prolongaciones, } \\
\text { poco elevada, presencia de pigmento de color plomo. }\end{array}$ \\
\hline III-300A & $\begin{array}{l}\text { Blanca, yesosa, agrietada, poco micelio profundo, cultivo } \\
\text { cristalino y presencia de micelio sedimentado. }\end{array}$ & $\begin{array}{l}\text { Blanca opaca, yesosa, borde irregular, poco elevada, pigmento } \\
\text { marrón rojizo oscuro bajo la colonia. }\end{array}$ \\
\hline III-300B & $\begin{array}{l}\text { Blanca, yesosa, poco abrupta, con poco micelio profundo, sin } \\
\text { micelio libre pero con sedimentado. }\end{array}$ & $\begin{array}{l}\text { Blanca opaca, yesosa, borde irregular, pulverulenta, plana, } \\
\text { pigmento color marrón rojizo. }\end{array}$ \\
\hline III-400A & $\begin{array}{l}\text { Blanca, cremosa, yesosa y superficial, con micelio profundo, } \\
\text { cultivo cristalino, micelio sedimentado. }\end{array}$ & $\begin{array}{l}\text { Blanca, borde irregular, corrugada, ligeramente elevada, } \\
\text { presencia de pigmento color marrón rojizo. }\end{array}$ \\
\hline III-400B & $\begin{array}{l}\text { Blanca, cremosa, yesosa, superficial, sin micelio profundo, } \\
\text { escasos conglomerados, micelio marrón sedimentado. }\end{array}$ & $\begin{array}{l}\text { Crema-rojizo, circular, } 8 \mathrm{~mm} \text { de diámetro, borde irregular, } \\
\text { poco elevada. }\end{array}$ \\
\hline
\end{tabular}


colonias circulares con borde liso y las colonias de bordes muy irregulares (festoneados, dactiliformes y dentados). En muchos casos fue posible observar colonias con superficie crateriforme y corrugada con anillos concéntricos de pigmentación variable (Figura 1). Asimismo, el color de las colonias variaron desde blancas sin pigmentación en superficie $(37,1 \%)$ a grisáceas (29,03\%), tal como se puede observar en la Figura 2; presentándose además pigmentaciones intermedias como blanco-rosáceas $(16,12 \%)$, cremas $(12,9 \%)$ y blanco-amarillentas $(4,83 \%)$. Los actinomycetes en la base de sus respectivas colonias presentaron pigmentación que variaron desde marrón oscuro, rojizo hasta amarillo pálido. Fue muy frecuente observar colonias grisáceas con puntos blancos en el centro y muchas veces con exudados. La capacidad de formar anillos concéntricos en el medio parece ser una respuesta quimiotrófica inducida por el gradiente de nutrientes en el medio y la temperatura de incubación, ya que en nuestro caso fue posible observar este comportamiento sobre todo en las colonias mantenidas en refrigeración. Muchas de estas características fueron también observadas por Magarvey et al. (2004) para actinobacterias miembros de la familia Micromonosporaceae. Observaciones microscópicas mostraron células filamentosas y finamente ramificadas, todas ellas Gram positivas. En medio líquido sin agitación se pudo observar que la gran mayoría de los actinomycetes iniciaron su desarrollo formando una gran película en superficie hasta formar colonias muy bien definidas (Figura 3A), en cambio otros se adhirieron fuertemente a las paredes del tubo, pero con el transcurrir del tiempo se observó la formación de micelios en la superficie de esta película, indicando que la colonia está en la fase de maduración de esporas por lo que adquiere una apariencia pulverulenta y yesosa. En los cultivos con agitación, los actinomycetes crecieron de manera peculiar (Figura 3B); pues algunos inicialmente formaron pequeńos conglomerados de micelio en la parte inferior del medio para luego aparecer colonias secas en la superficie; por el contrario, otras cepas iniciaron su crecimiento en la parte superior a veces adheridas a las paredes del tubo y a manera de colonias pequeńas y brillosas que viene a ser la fase de crecimiento y formación de tirabuzón. Tardíamente formaron precipitados de colonias algodonosas. Estas características fueron también observadas por Maldonado et al. (2005) en la descripción de nuevos Actinomycetes de sedimentos marinos con especies dominantes del género Micromonospora, Rhodococcus y Streptomyces.

Por otro lado, el olor a "tierra húmeda" (geosmina) característica de muchos actinomycetes de origen terrestre, se percibe de manera indistinta en los actimomycetes marinos ya sea en el medio líquido o sólido. $\mathrm{Al}$ respecto, Zaitlin et al. (2003) considera que la producción de geosmina es particularmente variable sobre todo en actinomycetes de origen continental.

Asimismo, los microcultivos de actinomycetes realizados por el método de "bloques de agar" resultaron ser más útiles que el método de "laminilla en plano inclinado", ya que se pudo observar mejor microscópicamente las estructuras vegetativas y de fructificación de los actinomycetes marinos en estudio (Fig. 5).

\section{Producción de Enzimas Extracelulares por actino- mycetes marinos}

La totalidad de cepas de actinomycetes marinos producen algún tipo de enzima extracelular (Tabla 3). Se ha determinado cualitativamente la producción de enzimas hidrolíticas en la mayoría de los aislados, siendo $96 \%$ productores de esterasas,
Tabla 3. Actividad multienzimática de actinomycetes aislados de sedimento marino de las bahías de Ancón e Independencia.

\begin{tabular}{|c|c|c|c|c|c|}
\hline $\begin{array}{l}\text { Actinomycete } \\
\quad(\mathrm{n}=62)\end{array}$ & 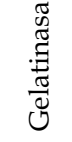 & $\begin{array}{l}\tilde{D} \\
\mathscr{\Xi} \\
\stackrel{\Xi}{\tilde{D}} \\
\tilde{D} \\
\tilde{U}\end{array}$ & $\frac{\mathbb{O}}{\mathbb{\pi}}$ & 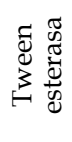 & 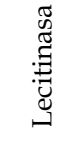 \\
\hline M11-105 & + & - & + & + & ++ \\
\hline M11-106 & ++ & +++ & + & ++ & ++ \\
\hline M11-110 & ++ & +++ & ++ & ++ & +++ \\
\hline M11-115 & ++ & +++ & + & + & $\mathrm{NC}$ \\
\hline M11-118 & ++ & - & +++ & + & ++ \\
\hline M11-120 & +++ & +++ & ++ & ++ & +++ \\
\hline M11-121 & $\mathrm{NC}$ & $\mathrm{NC}$ & + & + & ++ \\
\hline M11-123 & + & + & + & ++ & ++ \\
\hline M11-125 & ++ & +++ & ++ & +++ & +++ \\
\hline M11-131 & ++ & ++ & + & $\mathrm{NC}$ & + \\
\hline M11-133 & +++ & +++ & +++ & +++ & +++ \\
\hline EM-2005 & ++ & ++ & + & +++ & +++ \\
\hline M10-85 & ++ & ++ & $\mathrm{NC}$ & +++ & ++ \\
\hline M12-141 & ++ & ++ & ++ & +++ & ++ \\
\hline M10-77 & + & - & +++ & ++ & + \\
\hline AC16 & + & - & $\mathrm{NC}$ & ++ & ++ \\
\hline I-34A & ++ & - & + & ++ & $\mathrm{NC}$ \\
\hline I-34B & + & - & + & ++ & ++ \\
\hline I-234 & + & - & +++ & +++ & ++ \\
\hline I- $334 \mathrm{~A}$ & + & ++ & ++ & +++ & +++ \\
\hline I-334B & ++ & +++ & +++ & +++ & +++ \\
\hline I-434A & + & - & ++ & +++ & ++ \\
\hline I-434B & + & - & + & ++ & ++ \\
\hline I-534 & +++ & +++ & +++ & +++ & +++ \\
\hline I-100A & ++ & ++ & + & +++ & $\mathrm{NC}$ \\
\hline I-100B & + & + & + & + & - \\
\hline $\mathrm{I}-300 \mathrm{~A}$ & + & - & + & ++ & ++ \\
\hline I-300B & + & - & + & ++ & ++ \\
\hline $\mathrm{I}-300 \mathrm{C}$ & + & - & + & ++ & ++ \\
\hline $\mathrm{I}-400 \mathrm{~A}$ & + & - & + & ++ & ++ \\
\hline $\mathrm{I}-400 \mathrm{~B}$ & + & - & ++ & ++ & ++ \\
\hline $\mathrm{I}-400 \mathrm{C}$ & + & - & + & + & ++ \\
\hline II-334A & $\mathrm{NC}$ & ++ & ++ & - & + \\
\hline II-334B & + & + & + & ++ & ++ \\
\hline II-334C & + & + & + & ++ & ++ \\
\hline II-534 & ++ & +++ & +++ & +++ & +++ \\
\hline II-300A & ++ & ++ & ++ & +++ & +++ \\
\hline II-300B & ++ & +++ & +++ & +++ & +++ \\
\hline II-400A & ++ & +++ & + & +++ & ++ \\
\hline II-400B & $\mathrm{NC}$ & +++ & - & + & - \\
\hline III-234A & ++ & ++ & ++ & +++ & ++ \\
\hline III-234B & ++ & ++ & ++ & +++ & ++ \\
\hline III-234C & ++ & + & ++ & +++ & ++ \\
\hline III-234D & ++ & ++ & ++ & +++ & +++ \\
\hline III-234E & ++ & ++ & +++ & +++ & +++ \\
\hline III-434A & ++ & ++ & ++ & +++ & ++ \\
\hline III-434B & + & + & + & ++ & ++ \\
\hline III-434C & ++ & ++ & ++ & +++ & + \\
\hline III-434D & ++ & ++ & +++ & +++ & ++ \\
\hline III-434E & ++ & ++ & ++ & +++ & + \\
\hline III-434F & +++ & +++ & $\mathrm{NC}$ & +++ & $\mathrm{NC}$ \\
\hline III-200A & ++ & +++ & +++ & +++ & - \\
\hline III-200B & +++ & +++ & +++ & +++ & $\mathrm{NC}$ \\
\hline III-200C & ++ & +++ & +++ & +++ & +++ \\
\hline III-200D & ++ & +++ & +++ & +++ & +++ \\
\hline III-200E & +++ & +++ & +++ & +++ & +++ \\
\hline III-200F & +++ & +++ & +++ & +++ & +++ \\
\hline III-200G & ++ & +++ & +++ & +++ & +++ \\
\hline III-300A & ++ & ++ & ++ & +++ & ++ \\
\hline III-300B & +++ & ++ & ++ & +++ & ++ \\
\hline III-400A & ++ & +++ & ++ & +++ & +++ \\
\hline III-400B & +++ & ++ & ++ & +++ & +++ \\
\hline
\end{tabular}

Halos de actividad enzimática (radio): ( -$)$ sin actividad; (NC) no crecimiento; $(+)<8 \mathrm{~mm} ;(++) 8-16 \mathrm{~mm} ;(+++)>16 \mathrm{~mm}$ 


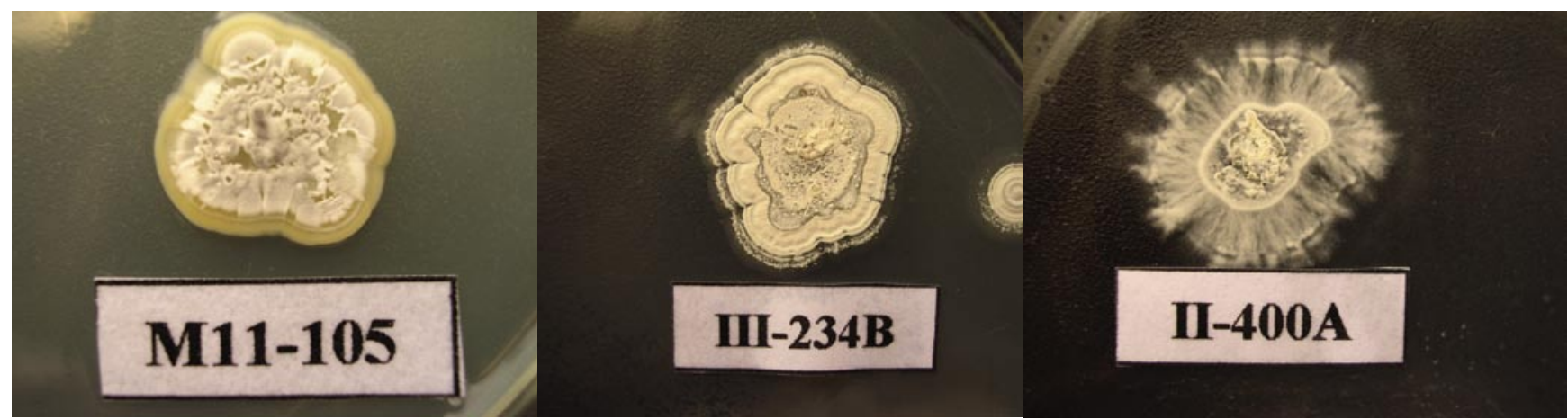

Figura 1. Diversidad morfológica de colonias de actinomycetes de origen marino aislados de sedimentos de la costa central del Perú (Bahías de Ancón e Independencia).

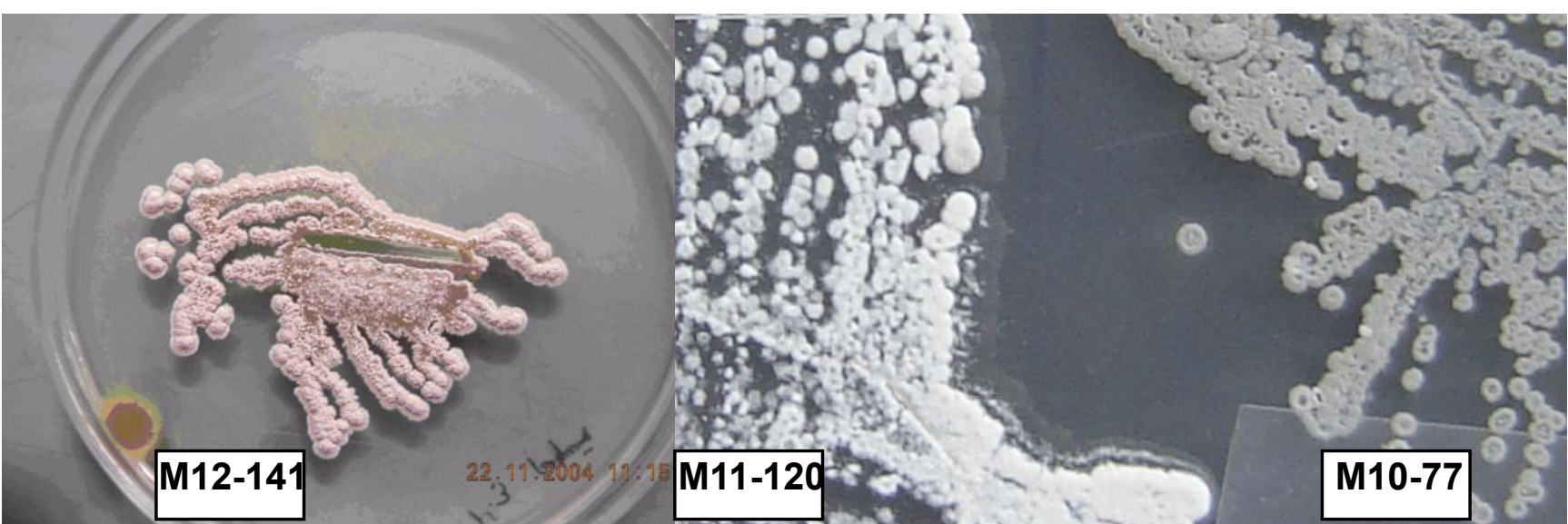

Figura 2. Pigmentaciones de colonia de Actinomycetes (100 m de profundidad, Bahía de Independencia) con actividad antimicrobiana. Colonias rosáceas (M12-141), blancas (M11-120) y grisáceas (M10-77)

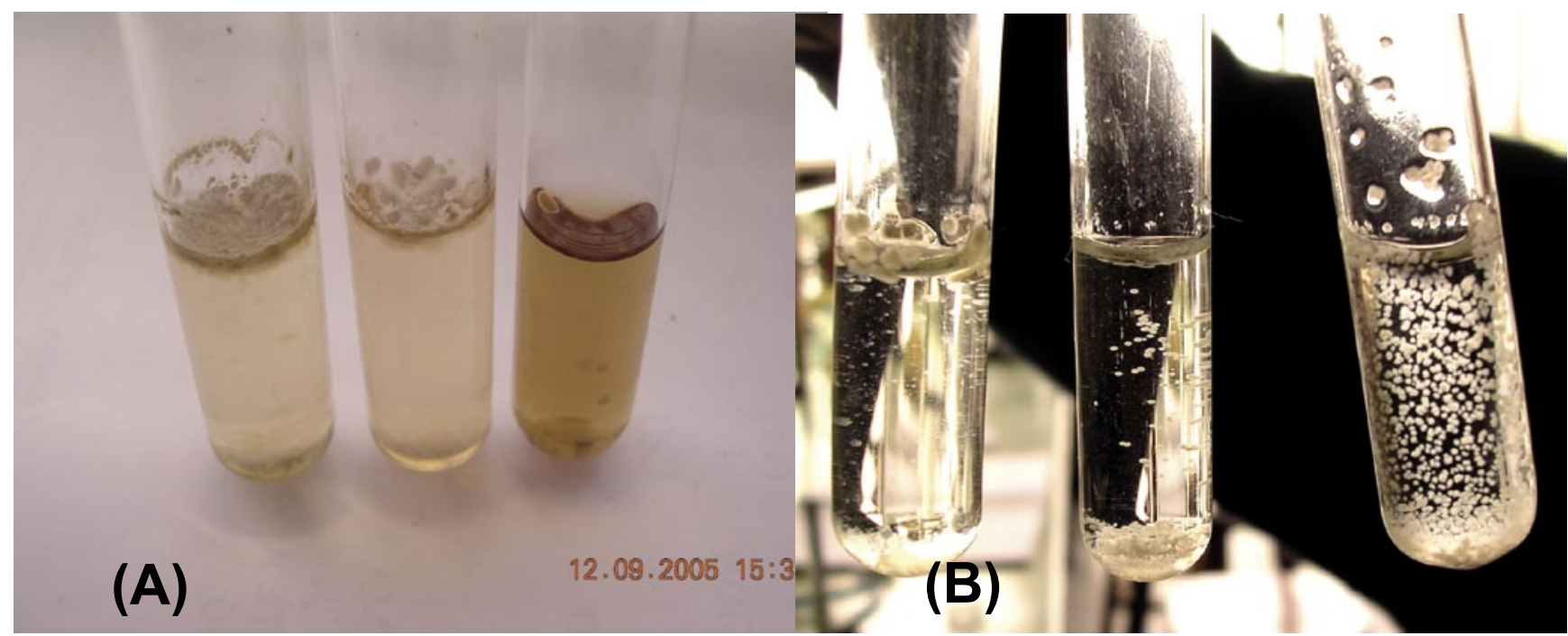

Figura 3. Comportamiento cultural de actinomycetes marinos. (A) película gruesa en superficie y producción de pigmento marrón difusible; B: película gruesa en superficie (izquierdo), precipitado denso (centro) y microcolonias en suspensión (derecho).

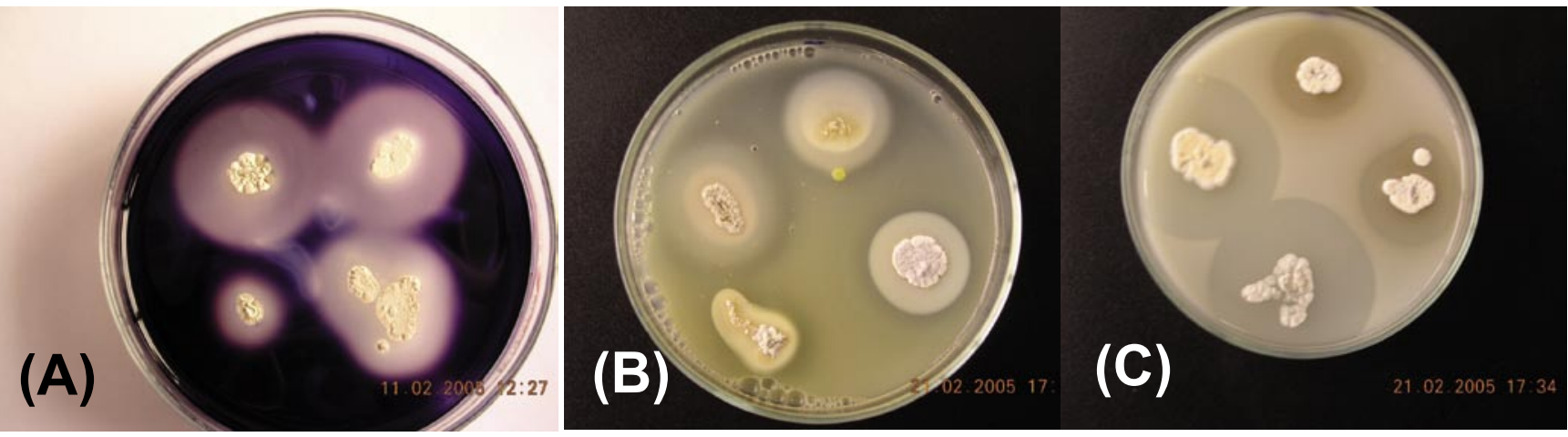

Figura 4. Producción de Enzimas Extracelulares por Actinomycetes aislados de sedimento marino: cepas amilolíticas (A), lipolíticas (B) y proteolíticas (C). 


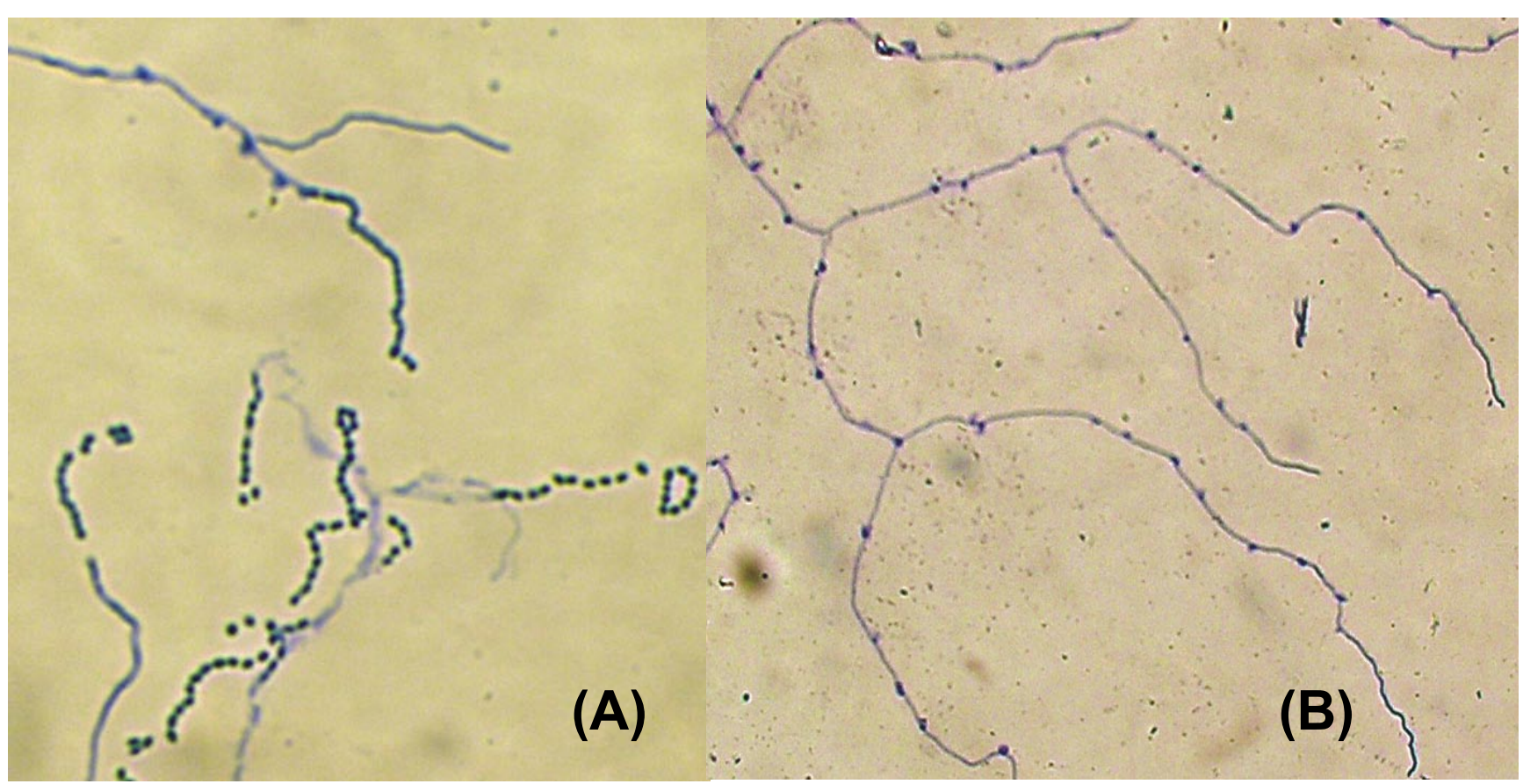

Figura 5. Observación microscópica de Actinomycetes marinos, A: cepa M10-77 identificada como Streptomyces; B: cepa M11-120, miembro del grupo Thermoactinomycetes.

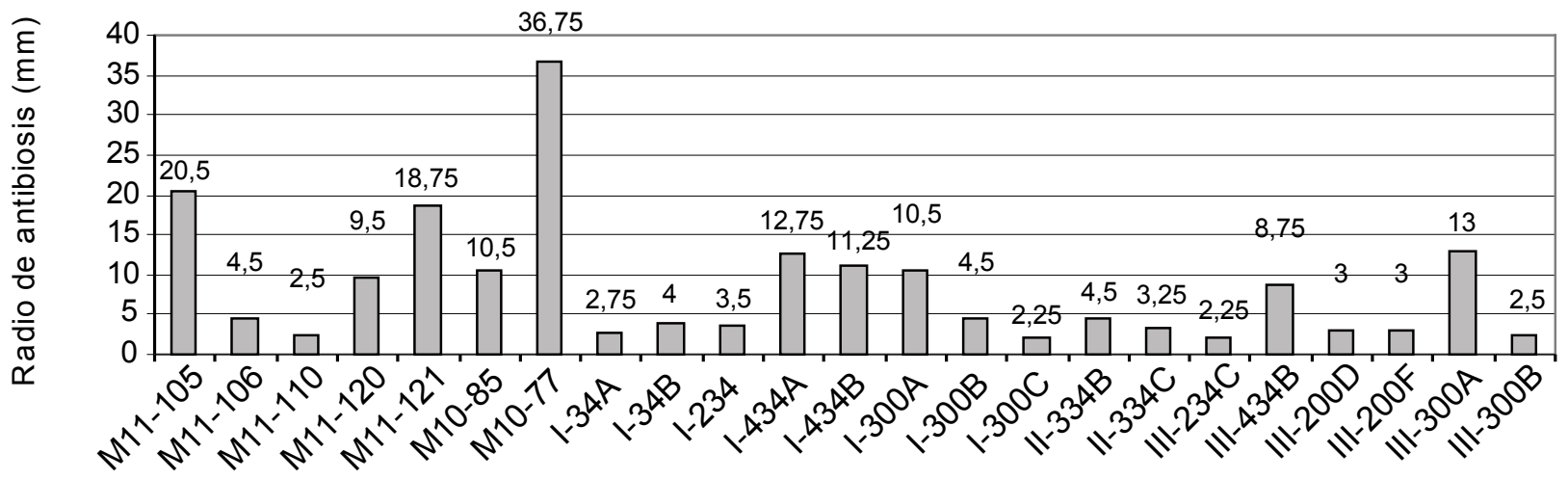

\section{Actinomycetes}

Figura 6. Actividad antimicrobiana de una colección de 23 Actinomycetes marinos frente a una cepa multidrogorresistente de Staphylococcus aureus cepa 457.

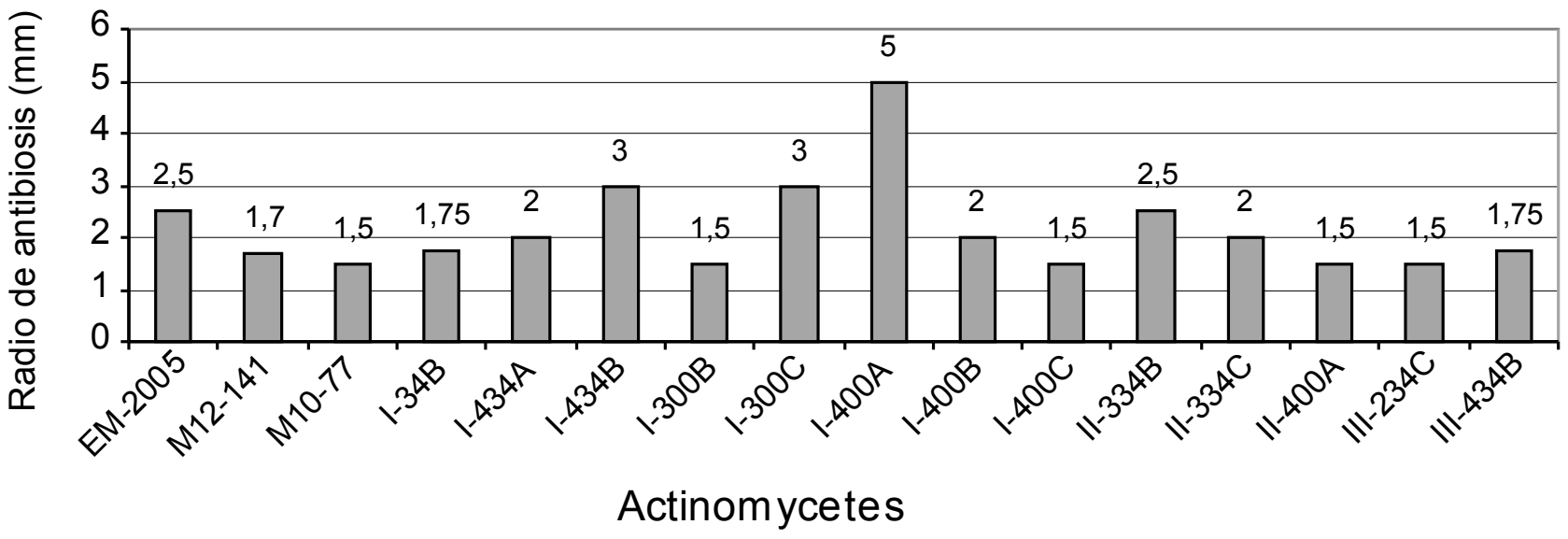

Figura 7. Actividad antimicrobiana de una colección de 16 Actinomycetes marinos frente a una cepa multidrogorresistente de Pseudomonas aeruginosa cepa 657. 
Tabla 4. Actividad inhibitoria de 62 cepas de actinomycetes aislados de sedimento marino frente a bacterias multi-drogoresistentes y levaduras patógenas de origen clínico.

\begin{tabular}{|c|c|c|c|c|}
\hline 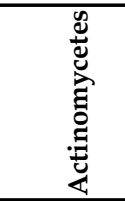 & 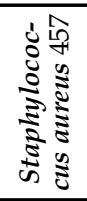 & 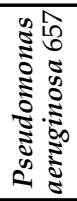 & 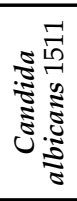 & 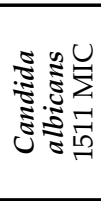 \\
\hline M11-105 & ++ & - & - & - \\
\hline M11-106 & + & + & - & - \\
\hline M11-110 & + & - & - & - \\
\hline M11-115 & - & + & - & - \\
\hline M11-118 & - & - & - & - \\
\hline M11-120 & + & + & ++ & - \\
\hline M11-121 & ++ & - & - & - \\
\hline M11-123 & - & - & - & - \\
\hline M11-125 & - & + & + & + \\
\hline M11-131 & - & - & - & - \\
\hline M11-133 & - & + & - & - \\
\hline EM-2005 & - & + & - & - \\
\hline M10-85 & ++ & + & + & + \\
\hline M12-141 & + & + & ++ & - \\
\hline M10-77 & ++++ & + & + & + \\
\hline AC16 & + & - & - & - \\
\hline I-34A & + & + & - & - \\
\hline I-34B & + & + & + & - \\
\hline I-234 & + & + & - & + \\
\hline I-334A & - & + & - & - \\
\hline I-334B & - & - & - & - \\
\hline $\mathrm{I}-434 \mathrm{~A}$ & ++ & + & + & + \\
\hline I-434B & ++ & + & + & + \\
\hline I-534 & - & - & - & - \\
\hline I-100A & + & + & - & - \\
\hline I-100B & - & - & - & - \\
\hline $\mathrm{I}-300 \mathrm{~A}$ & ++ & + & + & + \\
\hline I-300B & + & + & + & + \\
\hline I-300C & + & + & + & + \\
\hline $\mathrm{I}-400 \mathrm{~A}$ & + & + & + & + \\
\hline I-400B & + & + & + & + \\
\hline I-400C & - & + & - & - \\
\hline II-334A & - & - & + & + \\
\hline II-334B & + & + & + & + \\
\hline II-334C & + & + & + & + \\
\hline II-534 & - & - & - & - \\
\hline II-300A & - & + & - & - \\
\hline II-300B & - & + & - & - \\
\hline II-400A & - & + & - & - \\
\hline II-400B & - & - & - & - \\
\hline III-234A & - & + & - & - \\
\hline III-234B & - & + & - & - \\
\hline III-234C & + & + & - & - \\
\hline III-234D & + & - & - & - \\
\hline III-234E & + & + & - & - \\
\hline III-434 ${ }^{\mathrm{a}}$ & - & - & - & - \\
\hline III-434B & + & + & + & - \\
\hline III-434C & - & - & - & - \\
\hline III-434D & - & + & - & - \\
\hline III-434E & - & - & - & - \\
\hline III-434F & - & - & - & - \\
\hline III-200A & - & - & - & - \\
\hline III-200B & - & + & - & - \\
\hline III-200C & - & - & - & - \\
\hline III-200D & + & - & - & - \\
\hline III-200E & - & - & - & - \\
\hline III-200F & + & - & - & - \\
\hline III-200G & - & - & - & - \\
\hline III-300 & ++ & + & - & - \\
\hline III-300B & + & + & - & - \\
\hline III-400 & + & - & - & - \\
\hline III-400B & - & - & - & - \\
\hline
\end{tabular}

Halos de inhibición (mm de radio): $0<->, 1-10<+>, 11-20<++>, 21-$ $30<+++>, 30$ a más $<++++>$
95\% de gelatinasas, $92 \%$ de amilasas, $88 \%$ de lecitinasas y $74 \%$ de caseinasas. Los actinomycetes marinos que mostraron mayor actividad enzimática fueron los productores de caseinasa. Igualmente los actinomycetes productores de lipasas (Tween esterasas y lecitinasas) fueron muy significativas, tal como se puede observar en la Figura 4. Se resalta a las cepas M11-133, I-534, III-200E y III-200F como las más significativas en la producción de las 5 enzimas extracelulares determinadas en este estudio (Tabla 3). Con el advenimiento de la biotecnología la demanda y la búsqueda de enzimas microbianas con nuevas propiedades ha incrementado enormemente su interés por el estudio de actinomycetes marinos. Actualmente, han sido reconocidos muchos microorganismos marinos como potenciales fuentes de nuevas enzimas de uso industrial como fosfatasas, arilsulfatasas, quitinasas, L-asparaginasas, L-glutaminasas, amilasas, proteasas, lipasas, celulasas, ureasas y lactamasas. En la producción de estas y otras enzimas están involucradas bacterias marinas como Vibrio, Pseudomonas y miembros de Actinomycetes como Streptoverticillium (Chandrasekaran, 1997). Si se toma en cuenta que actualmente tienen importancia industrial prioritariamente los microorganismos ambientales termófilos y psicrófilos, los actinomycetes marinos por su hábitat son considerados psicrófilos moderados; por ello, los actinomycetes aislados en este trabajo adquieren relevancia biotecnológica debido a la capacidad de producir diversas enzimas extracelulares bajo condiciones de laboratorio.

\section{Actividad antibacteriana}

Del total de 62 actinomycetes marinos evaluados, 31 cepas (50\%) mostraron actividad antibacteriana frente al patógeno multirresistente Staphylococcus aureus; 36 (59\%) frente a Pseudomonas aeruginosa y 23 (37\%) a ambos patógenos (Tabla 4). Las cepas de actinomycetes marinos signadas como M10-77 e I-400A identificadas respectivamente como Streptomyces y Thermoactinomyces (Tabla 5) fueron las que exhibieron mayor actividad inhibitoria frente a $S$. aureus 457 (Figura 6) y P. aeruginosa 657 (Figura 7) respectivamente. Se destaca la efectividad de los actinomycetes aislados demostrada por las pruebas de antagonismo in vitro frente a $S$. aureus cepa 457 un patógeno aislado de aspirado de catéter y declarado multidrogorresistente en el área de patología del Instituto Especializado del Niño con resistencia a 8 drogas de un total de 10 de uso convencional en el tratamiento de Gram positivas (Tabla 7). Estos resultados son prometedores si se considera que la aparición de cepas Staphylococcus aureus meticilino-resistentes (MRSA) son cada vez más frecuentes en todo el mundo. En el Perú, la presencia de MRSA está registrada en varios reportes, entre ellas los trabajos de Mendoza et al. (2003). En otras latitudes, Sujatha et al. (2005), describen el aislamiento y la caracterización de Streptomyces psammoticus cepa BT-480 productora de un antibiótico poliketide SBR-22 efectiva contra S. aureus meticilino-resistentes. Asimismo, Magarvey et al. (2004) describen a 17 cepas de actinomycetes aislados de sedimento marino con diversas actividades biológicas, entre ellas inhibitorias de $S$. aureus meticilino-resistentes, Enterococcus vancomicina-resistentes, Cryptococcus neoformans y Candida albicans. En el caso de Pseudomonas aeruginosa, la multirresistencia antibiótica es ampliamente conocida, sobre todo si el patógeno tiene un origen intrahospitalario. Si bien, los actinomycetes marinos aislados en este trabajo son cuantitativamente mayor que las que actuaron frente a $S$. aureus, cualitativamente mostraron actividad discreta sobre $P$. aeruginosa; sin embargo, se debe considerar que son muy pocas las bacterias ambientales que muestran actividad antagónica 
Tabla 5. Identificación supragenérica de cepas seleccionadas de actinomycetes marinos y su actividad antimicrobiana frente a patógenos de origen clínico.

\section{Cepa testigo}

\begin{tabular}{|c|c|c|c|}
\hline $\begin{array}{l}\text { Actinomycetes marinos } \\
\qquad(\mathrm{n}=14)\end{array}$ & Identificación supragenérica & Staphylococcus aureus 457 & Pseudomonas aeruginosa 657 \\
\hline M11-120 & $\begin{array}{c}\text { Grupo } 28 \\
\text { Thermoactinomycetes }\end{array}$ & $9,50\left(^{*}\right)$ & 0,25 \\
\hline M10-85 & $\begin{array}{c}\text { Grupo } 25 \\
\text { Streptomycetes }\end{array}$ & 10,50 & 1,00 \\
\hline M12 141 & Grupo 26 Maduromycetes & 0,25 & 1,70 \\
\hline M10-77 & $\begin{array}{c}\text { Grupo } 25 \\
\text { Streptomycetes }\end{array}$ & 36,75 & 1,50 \\
\hline $\mathrm{I}-34 \mathrm{~B}$ & $\begin{array}{c}\text { Grupo } 25 \\
\text { Streptomycetes }\end{array}$ & 4,00 & 1,75 \\
\hline $\mathrm{I}-434 \mathrm{~A}$ & NI & 12,75 & 2,00 \\
\hline $\mathrm{I}-434 \mathrm{~B}$ & NI & 11,25 & 3,00 \\
\hline $\mathrm{I}-300 \mathrm{~A}$ & $\begin{array}{c}\text { Grupo } 22 \\
\text { Nocardiformes }\end{array}$ & 10,50 & 0,25 \\
\hline $\mathrm{I}-300 \mathrm{~B}$ & NI & 4,50 & 1,50 \\
\hline $\mathrm{I}-300 \mathrm{C}$ & NI & 2,25 & 3,00 \\
\hline $\mathrm{I}-400 \mathrm{~A}$ & $\begin{array}{c}\text { Grupo } 28 \\
\text { Thermoactinomycetes }\end{array}$ & 1,50 & 5,00 \\
\hline $\mathrm{I}-400 \mathrm{~B}$ & $\begin{array}{c}\text { Grupo } 25 \\
\text { Streptomycetes }\end{array}$ & 1,50 & 2,00 \\
\hline II-334B & $\begin{array}{c}\text { Grupo } 25 \\
\text { Streptomycetes }\end{array}$ & 4,50 & 2,50 \\
\hline
\end{tabular}

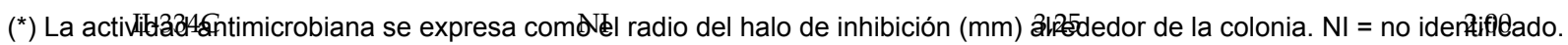

Tabla 6. Actividad antifúngica de 17 cepas seleccionadas de actinomycetes marinos frente a hongos miceliales y levaduras de origen clínico.

\begin{tabular}{|c|c|c|c|c|c|}
\hline \multirow[b]{2}{*}{ 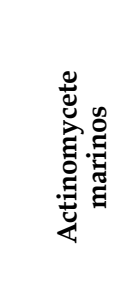 } & \multicolumn{5}{|c|}{ Cepa indicadora } \\
\hline & 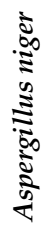 & 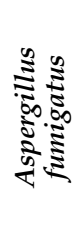 & 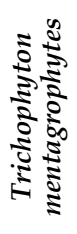 & 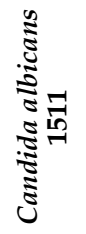 & 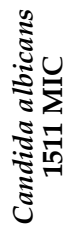 \\
\hline M11-120 & 0 & 0 & 0 & $14\left(^{*}\right)$ & 0 \\
\hline M11-125 & 0 & 0 & 0 & 2,5 & 0,5 \\
\hline M10-85 & 0 & 0 & 0 & 7,5 & 0,5 \\
\hline M12-141 & 0 & 0 & 0 & 13,5 & 0 \\
\hline M10-77 & 0 & 0 & 0 & 5 & 0,5 \\
\hline I-34B & 0 & 0 & 0 & 1,5 & 0 \\
\hline $\mathrm{I}-434^{\mathrm{a}}$ & 0 & 0 & 0 & 4 & 0,5 \\
\hline I-434B & 0 & 0 & 0 & 5 & 3 \\
\hline $\mathrm{I}-300^{\mathrm{a}}$ & 0 & 0 & 0 & 5 & 1 \\
\hline I-300B & 0 & 0 & 0 & 5 & 4 \\
\hline I-300C & 0 & 0 & 0 & 4 & 0,5 \\
\hline $\mathrm{I}-400^{\mathrm{a}}$ & 0 & 0 & 0 & 5 & 1 \\
\hline I-400B & 0 & 0 & 0 & 5 & 5 \\
\hline II- $334^{\mathrm{a}}$ & 0 & 0 & 0 & 3,5 & 2 \\
\hline II-334B & 0 & 0 & 0 & 5 & 2,5 \\
\hline II-334C & 0 & 0 & 0 & 5 & 1,5 \\
\hline III-434B & 0 & 0 & 0 & 4 & 0 \\
\hline
\end{tabular}

(*) La actividad antifúngica se expresa como el diámetro del halo de inhibición $(\mathrm{mm})$ alrededor de la colonia.
Tabla 7. Origen y localización de las cepas testigo drogo-multirresistentes de Pseudomonas aeruginosa y Staphylococcus aureus, en el Instituto Especializado del Niño, Lima - Perú.

\begin{tabular}{|c|c|c|c|c|c|}
\hline \multicolumn{3}{|c|}{ Pseudomonas aeruginosa } & \multicolumn{3}{|c|}{ Staphylococcus aureus } \\
\hline \multicolumn{3}{|c|}{ Localización: Cardiología } & \multicolumn{3}{|c|}{ Localización: Medicina } \\
\hline \multicolumn{3}{|c|}{ Código de la muestra: 657} & \multicolumn{3}{|c|}{ Código de la muestra: 457} \\
\hline \multicolumn{3}{|c|}{$\begin{array}{l}\text { Tipo de muestra: } \\
\text { Aspirado traqueal }\end{array}$} & \multicolumn{3}{|c|}{$\begin{array}{l}\text { Tipo de muestra: } \\
\text { Aspirado de catéter }\end{array}$} \\
\hline Antibiótico & $(*)$ & $\begin{array}{l}\text { Halo } \\
\text { inhib. } \\
(\mathrm{mm})\end{array}$ & Antibiótico & $(*)$ & $\begin{array}{l}\text { Halo } \\
\text { inhib. } \\
(\mathrm{mm})\end{array}$ \\
\hline Carbenicilina & $\mathrm{R}$ & 6 & Penicilina & $\mathrm{R}$ & 6 \\
\hline Imipenem & $\mathrm{R}$ & 11 & Oxacilina & $\mathrm{R}$ & 6 \\
\hline Amicacina & $\mathrm{S}$ & 18 & Gentamicina & $\mathrm{R}$ & 6 \\
\hline Ciprofloxacina & $\mathrm{S}$ & 26 & Eritromicina & $\mathrm{R}$ & 6 \\
\hline Ceftazidina & $\mathrm{R}$ & 6 & Tetraciclina & $\mathrm{S}$ & 25 \\
\hline Aztreonam & I & 17 & Cloramfenicol & $\mathrm{R}$ & 6 \\
\hline Gentamicina & $\mathrm{R}$ & 6 & Clindamicina & $\mathrm{R}$ & 6 \\
\hline \multirow[t]{3}{*}{ Meropenem } & $\mathrm{R}$ & 6 & Rifampicina & $\mathrm{S}$ & 31 \\
\hline & & & Sulfamet+Trime & $\mathrm{R}$ & 6 \\
\hline & & & Ciprofloxacina & $\mathrm{R}$ & 6 \\
\hline
\end{tabular}

(*) R: resistente; S: sensible; I: intermedio 


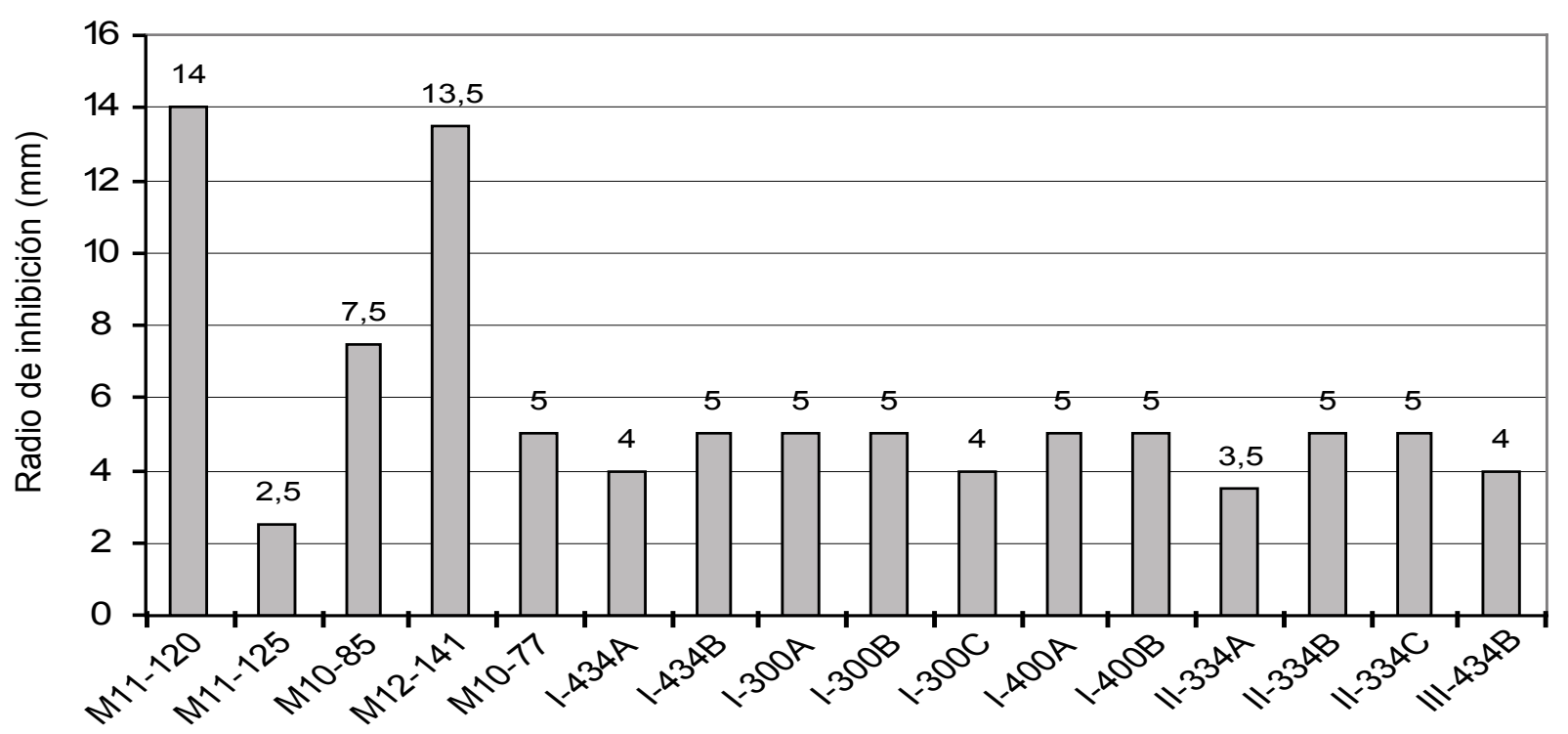

Actinomycetes

Figura 8. Actividad antifúngica de 16 Actinomycetes aislados de sedimento marino frente a una cepa patógena de Candida albicans cepa 1511.

a Gram negativos patógenos como Pseudomonas aeruginosa, Escherichia coli, Vibrio cholerae, Aeromonas hydrophila, entre otros. En consecuencia, nuestros resultados difieren ampliamente de otros trabajos, en especial de los reportados por Kokare et al (2004), quienes de un total de 20 cepas bioactivas de actinomycetes, marinos determinan que 16 de ellas presentan fuerte actividad antagónica frente a microorganismos Gram positivos y solamente 2 de ellas frente a Gram negativos.

\section{Actividad antifúngica}

De las 62 cepas de actinomycetes marinos evaluados por su actividad antifúngica, 17 actinomycetes (27,42\%) mostraron tener actividad frente a cultivos de Candida albicans cepa 1511 y $13(20,97 \%)$ frente a Candida albicans cepa 1511MIC (Tabla 6; Figura 8 y Figura 9), siendo las cepas M11-120 (Thermoactinomycete) y M12-141 (Maduromycete) las de mayor actividad

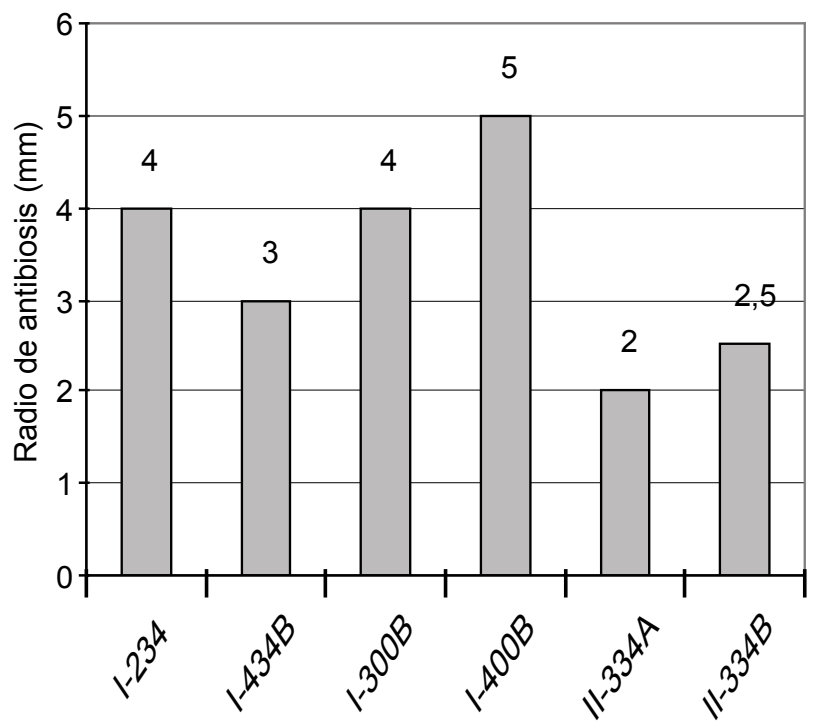

Actinomycetes

Figura 9. Actividad antifúngica de 6 Actinomycetes marinos frente al patógeno Candida albicans cepa 1511 MIC. antagónica frente a la levadura patógena Candida albicans cepa 1511, pero no así a la cepa 1511 MIC. Cabe resaltar que estos resultados son prometedores si se considera que los antimicóticos de uso clínico son escasos, las candidiasis y micosis causadas por hongos dematiáceos constituyen enfermedades emergentes y en general tiene creciente importancia como agentes oportunistas en pacientes inmunocomprometidos e incluso inmunocompetentes, a lo cual hay que agregar el incremento de la resistencia al escaso número de antifúngicos existentes (Pujol et al., 2000). Por otro lado, en el presente trabajo ningún actinomycete marino presentó actividad inhibitoria frente a otros hongos miceliales de origen clínico tales como Aspergillus niger, Aspergillus fumigatus y Trichophyton mentagrophytes (Tabla 6). Al respecto, existen muy pocos datos sobre el rol antagónico de actinomycetes marinos frente a hongos causantes de micosis en humanos, aunque Magarvey et al. (2004) describen el aislamiento de 3 cepas marinas con actividad antagónica a Candida albicans; y Kokare et al. (2004) señalan que de un total de 80 actinomycetes marinos lograron aislar 7 con gran actividad antifúngica. Igualmente, Kathiresan et al. (2005), señalan que de 160 actinomycetes marinos enfrentados contra 4 principales hongos fitopatógenos, el 51\% fueron eficaces contra Helminthosporium oryzae y Pyricularia oryzae, el $31 \%$ contra Rhizoctonia solani y el 12,5\% contra Colletotrichum falcatum. Ante estos resultados, queda como tarea inmediata determinar si los actinomycetes aislados en el presente trabajo tienen algún efecto inhibitorio sobre hongos fitopatógenos de nuestro medio.

\section{Actividad inhibitoria de extractos de cultivos ob- tenidos con etil acetato}

El uso de solventes orgánicos para la obtención de principios activos a partir de cultivos microbianos es de aplicación frecuente en biotecnología. En este caso, a partir de un cultivo en agitación de la cepa elegida (M10-77) se ha logrado recoger extractos crudos con etil acetato, los cuales mostraron tener limitada capacidad inhibitoria contra el patógeno $S$. aureus cepa 457. Si bien, el resultado en este estudio es aún discreto, pues las medidas de los halos de inhibición generados por los extractos no superaron 
a $26 \mathrm{~mm}$ de radio, muy posiblemente una estandarización de la metodología brindará buen rendimiento en la extracción de principios activos a partir de cultivos de actinomycetes marinos. Trabajos similares al presente indican que es necesario probar varios solventes orgánicos y varias cepas indicadoras; así, Leiva et al. (2004) utilizando 5 solventes diferentes obtuvo mejores resultados con etilmetilcetona que tuvo un rendimiento muy activo contra Bacillus subtilis.

Futuros estudios de este tipo permitirán conocer la biodiversidad, biogeografía, distribución y el rol que cumplen los actinomycetes en los ecosistemas marinos; así como el potencial uso de sus productos en diversos campos de la biotecnología microbiana.

\section{Agradecimientos}

Los autores agradecen al Fondo de Desarrollo Universitario (FEDU) por el apoyo económico brindado al presente trabajo a través del Estudio No 061001201 del Consejo Superior de Investigaciones (CSI) de la UNMSM. Asimismo, expresamos nuestro agradecimiento a los miembros del Grupo de Investigación de Ecología Marina de la Facultad de Ciencias Biológicas - UNMSM a cargo del Dr. Juan Tarazona Barboza y el Blgo. Elmer Ramos Figueroa por su valiosa ayuda en la recolección de las muestras de sedimento marino.

\section{Literatura citada}

Augustine, S.K., S.P. Bhavsar \& B.P. Kapadnis. 2005. Production of a growth dependent metabolite active against dermatophytes by Streptomyces rochei AK 39. Indian J Med Res. 121(3):164-70.

Bull, A.T., J.E. Stach, A.C. Ward \& M. Goodfellow. 2005. Marine actinobacteria: perspectives, challenges, future directions Antonie Van Leeuwenhoek. 87(3):65-79.

Bull, A.T., A.C. Ward \& M. Goodfellow. 2000. Search and discovery strategies for biotechnology: the paradigm shift. Microbiol Mol. Biol. Rev. 64:573-606.

Chandrasekaran, M. 1997. Industrial enzymes from marine microorganisms: The Indian scenario. J. Mar. Biotech. 5(2-3): 86-89.

Fiedler, H.P., C. Bruntner, A.T. Bull, A.C. Ward, M. Goodfellow, O. Potterat, C. Puder \& G. Mihm. 2005. Marine actinomycetes as a source of novel secondary metabolites. Antonie Van Leeuwenhoek. 87(1):37-42.

Holt, J.G., N.R. Krieg, P.H.A. Sneath, J.T. Staley \& S.P. Williams. 1994. Bergey's Manual of Determinative Bacteriology. $9^{\mathrm{a}}$ ed. Williams \& Wilkins. Baltimore.

Jensen, P.R., T.J. Mincer, P.G. Williams \& W. Fenical. 2005. Marine actinomycete diversity and natural product discovery. Antonie Van Leeuwenhoek. 87(1):43-8.

Jiang, C.L. \& L.H. Xu. 1996. Diversity of aquatic actinomycetes in lakes of the middle plateau, Yunnan, China. Appl. Environ. Microbiol. 62(1): 249-253.

Kathiresan, K., R. Balagurunathan \& S. Masilamani. 2005. Fungicidal activity of marine actinomycetes against phytopathogenic fungi. Indian Journal of Biotech. 4: 271-276.

Kelecom, A. 2002. Secondary metabolites from marine microorganisms. An. Acad. Bras. Cienc. 74(1): 151-170.

Kokare, C.R., K.R. Mahadik, S.S. Kadam \& B.A. Chopade. 2004. Isolation of bioactive marine actinomycetes from sediments isolated from Goa and Maharashtra coastlines (west coast of India). Indian J. Mar. Sc. 248-256.
Leiva, S., M. Yañez, L. Zaror, H. Rodríguez \& H. García-Quintana. 2004. Actividad antimicrobiana de Actinomycetales aislados desde ambientes acuáticos de sur de Chile. Rev. Med. Chile; 132; 151-159.

León, J. y P. García-Tello. 1998. Cepas nativas del bacterioneuston marino y su actividad inhibitoria de bacterias ictiopatógenas. Rev. Per. Biol. 5 (1): $47-64$.

León, J., F. Pellón, V. Unda, J. David, C. Anaya y V. Mendoza. 2000. Producción de enzimas extracelulares por bacterias aisladas de invertebrados marinos. Rev. per. biol. 7 (2): $202-210$.

Magarvey, N.A., J.M. Keller, V. Bernan, M. Dworkin \& D.H. Sherman. 2004. Isolation and characterization of novel marinederived actinomycete taxa rich in bioactive metabolites. Appl Environ Microbiol. 70(12):7520-9.

Maldonado, L.A., J.E. Stach, W. Pathom-aree, A.C. Ward, A.T. Bull \& M. Goodfellow. 2005. Diversity of cultivable actinobacteria in geographically widespread marine sediments. Antonie Van Leeuwenhoek, 87(1):11-8.

Mendoza, C.A., R. Velásquez, L. Mercado, J. Ballón y C. Maguiña. 2003. Susceptibilidad antimicrobiana de Staphylococcus aureus sensible, con sensibilidad "BORDERLINE" y resistentes a la meticilina. Rev Med Hered 14(4): 181-185.

Mincer, T.J., P.R. Jensen, C.A. Kauffman \& W. Fenical. 2002. Widespread and persistent populations of a major new marine actinomycete taxon in ocean sediments. Appl. Envirom. Microbiol. 68:5005-5011.

Pisano, M.A., M.J. Sonner \& M. López. 1986. Aplication of pretrataments for the isolation of bioactive Actinomycetes from from marine sediments Appl. Microbiol Biotechnol.25: 285-288.

Projan, S.J. \& P.J. Youngman. 2002. Antimicrobials: news solutions badly need. Curr. Opin. Microbiol. 5:463-465.

Saadoun, I., K.M. Hameed \& A. Moussauui. 1999. Characterization and analysis of antibiotic activity of some aquatic actinomycetes. Microbios 99(394):173-9.

Sujatha, P., K.V. Bapi Raju \& T. Ramana. 2005. Studies on a new marine streptomycete BT-408 producing polyketide antibiotic SBR-22 effective against methicillin resistant Staphylococcus aureus. Microbiol Res. 160(2):119-26.

Takizawa, W., R.R. Colwell \& R.T. Hill. 1993. Isolation and Diversity of Actinomycetes in the Chesapeake Bay. Appl. Environ. Microbiol. 59(4): 997-1002

Ward, A.C. \& N. Bora. 2006. Diversity and biogeography of marine actinobacteria. Curr Opin Microbiol.9(3): 279-86.

Westerdahl, A., J. Olsson, S. Kjelleberg \& P. Conway. 1991. Isolation and characterization of turbot (Scophthalmus maximus) associated bacteria with inhibitory effects against Vibrio anguillarum. Appl. Environ. Microbiol. 57(8): 2223-2228.

Williams, S.T., S. Lanning \& E.M.H. Wellington. 1984. Ecology of actinomycetes, p. 481-528. In M. Goodfellow, M. Mordarky and ST Williams (ed.), The biology of the actinomycetes. Academic Press Ltd., London, United Kingdom.

World Health Organization. 2002. Global Strategy for Containment of Antimicrobial Resistance. Fact sheet $\mathrm{N}^{\circ}$ 194. Geneva: WHO.

Zaitlin, B., S. Watson, J. Ridal, T. Satchwill \& D. Parkinson. 2003. Actinomycetes in Lake Ontario: habitats and geosmin and MIB production. Journal AWWA, 95,2: 113-118.

Zaror, I. y A. Espinel-Ingroff. 1989. Pruebas de susceptibilidad fúngica frente a antimicóticos. Bol. Micol. 4: 77-90.

Zheng, L., W. Lin, X. Yan \& H. Chen. 2004. A primary study on antimicrobial and cytotoxic activity of marine bacteria. Ying Yong Sheng Tai Xue Bao. 15(9):1633-6. 